Article

\title{
Pt nanoparticles entrapped in ordered mesoporous carbons: An efficient catalyst for the liquid-phase hydrogenation of nitrobenzene and its derivatives
}

\author{
Junrui Li, Xiaohong Li*, Yue Ding, Peng Wu \\ Shanghai Key Laboratory of Green Chemistry and Chemical Processes, School of Chemistry and Molecular Engineering, East China Normal University, \\ Shanghai 200062, China
}

A R T I C L E I N F O

Article history:

Received 21 May 2015

Accepted 17 June 2015

Published 20 November 2015

\section{Keywords:}

Pt nanoparticle

Nitrobenzene compound

Liquid-phase hydrogenation

Ordered mesoporous carbon

\begin{abstract}
A B S T R A C T
Pt nanoparticles entrapped in ordered mesoporous CMK-3 carbons with p6mm symmetry were prepared using a facile impregnation method, and the resulting materials were characterized using X-ray diffraction spectroscopy, $\mathrm{N}_{2}$ adsorption-desorption, scanning electron microscopy, transmission electron microscopy, energy dispersive X-ray spectroscopy, and X-ray photoelectron spectroscopy. The Pt nanoparticles were highly dispersed in the CMK-3 with $43.7 \%$ dispersion. The Pt/CMK-3 catalyst was an effective catalyst for the liquid-phase hydrogenation of nitrobenzene and its derivatives under the experimental conditions studied here. The Pt/CMK-3 catalyst was more active than commercial Pt/C catalyst in most cases. A highest turnover frequency of $43.8 \mathrm{~s}^{-1}$ was measured when the Pt/CMK-3 catalyst was applied for the hydrogenation of 2-methyl-nitrobenzene in ethanol under optimal conditions. It is worthy of note that the Pt/CMK-3 catalyst could be recycled easily, and could be reused at least fourteen times without any loss in activity or selectivity for the hydrogenation of nitrobenzene in ethanol.
\end{abstract}

(C) 2015, Dalian Institute of Chemical Physics, Chinese Academy of Sciences. Published by Elsevier B.V. All rights reserved.

\section{Introduction}

The uses of aniline include its application as a raw chemical material for the synthesis of pharmaceuticals, an intermediary in the synthesis of dyes and pigments, and an additive for rubber processing. Aniline is primarily produced via the reduction of nitrobenzene, using either iron powder reduction, or catalytic hydrogenation. However, the iron powder reduction of nitrobenzene to obtain aniline has become less prevalent, because of the comparatively low catalytic ability and the non-environmentally friendly nature of the technique [1,2]. Currently, approximately $85 \%$ of aniline is obtained via the catalytic hydrogenation of nitrobenzene. $\mathrm{Cu}$, $\mathrm{Ni}$ or noble metal-based catalysts are typically involved in the hydrogenation of nitrobenzene. The intrinsic activities of $\mathrm{Cu}$ and Ni-based catalysts are extremely low, so stringent conditions are required to obtain a satisfactory catalytic performance [3-6]. Considering that noble metal catalysts exhibit excellent catalytic activity and long lifetimes, the use of noble metal catalysts for the hydrogenation of nitrobenzene is very attractive, despite the relatively high cost of noble metals.

Carbon material-supported Pt catalysts are widely applied in this research field [7-14]. Carbon material-supported Pt catalysts were first applied in hydrogenation reactions more

\footnotetext{
* Corresponding author. Tel/Fax: +86-21-62238590; E-mail: xhli@chem.ecnu.edu.cn

This work was supported by the National Natural Science Foundation of China (21273076 and 21373089), the Open Research Fund of Top Key Discipline of Chemistry in Zhejiang Provincial Colleges and Key Laboratory of the Ministry of Education for Catalysis Materials (Zhejiang Normal University, ZJHX2013), and Shanghai Leading Academic Discipline Project (B409).
}

DOI: 10.1016/S1872-2067(15)60937-8 | http://www.sciencedirect.com/science/journal/18722067 | Chin. J. Catal., Vol. 36, No. 11, November 2015 
than 30 years ago [7]. Activated carbon is typically used as a carbon support material for Pt or Pd nanoparticles. With the development of novel carbon materials, new forms of activated carbon such as activated carbon fibers (ACF) and activated carbon cloths (ACC) were prepared and applied in hydrogenation processes. For instance, ACC-supported Pt catalysts were applied for the hydrogenation of nitrobenzene by Solano and coworkers in 1997 [8]. The results showed that the Pt/ACC catalysts presented two singular advantages over granular activated carbons (for which data had been published previously): (1) they showed a remarkable ease of reduction, in that the Pt was reduced completely at $393 \mathrm{~K}$; and (2) they were stable at temperatures as high as $623 \mathrm{~K}$, and after long reduction time. In addition, there was a good linear relationship between the dispersion of the Pt and its activity, and the dispersion of the Pt could be controlled by changing the surface area of the ACC supports; the dispersion of the Pt was in turn responsible for the catalytic activity.

Carbon nanotubes (CNTs) are allotropes of carbon with a cylindrical nanostructure. CNTs have unusual properties that are valuable for nanotechnology, electronics, optics, and other materials science and technology fields. Owing to their extraordinary thermal conductivity, and their unique mechanical and electrical properties, CNTs can be applied in a wide variety of fields, including catalysis. In 2005, Li et al. [11] prepared CNT-supported Pt catalysts using an impregnation and reduction-precipitation method, and investigated their catalytic performance toward nitrobenzene hydrogenation under atmospheric pressure and ambient temperatures. The Pt/CNT catalyst showed superior activity for the hydrogenation of nitrobenzene, compared with Pt/AC (activated carbon) catalysts, and the authors ascribed the extraordinary activity of the Pt/CNT catalyst to the mesoporous structure of the acid-oxidized CNTs and the highly dispersed Pt. In 2010, Sun et al. [14] prepared multi-walled CNT (MWCNT)-supported ultrafine Pt nanoparticles via a facile route, with the aid of tip sonication. The loading of Pt on the MWCNTs reached 50\%, and the size of the Pt particles could be controllably tuned in the range of 1.9-3.5 nm, with a narrow size distribution. The Pt/MWCNT catalyst was applied to catalyze the hydrogenation of nitrobenzene under a constant hydrogen pressure of 4.0 MPa, and in solvent-free conditions. The Pt/MWCNTs showed a turnover frequency (TOF) of $66900 \mathrm{~h}^{-1}$, and superior selectivity for aniline, because of the strong interaction between the Pt nanoparticles and the mesoporous MWNTs support.

Ordered mesoporous carbon materials (OMCs) have attracted increasing interest, because of their large surface area, uniform pore size, unique porous architecture, and high thermal, chemical, and mechanical stabilities $[15,16]$. These features mean that OMCs are promising candidates for electrode materials [17], adsorbents [18], catalyst supports [19-25], and catalysts [26]. Among OMCs, CMK-3 OMCs with p6mm symmetry are particularly widely known and widely applied [21-23,25,27,28]. CMK-3 OMCs can be synthesized using a classic two-step nano-casting method, using mesoporous silica SBA-15 as a template, sucrose as a carbon source, sulfuric acid as a carbonization catalyst, and carbonization performed at
$1173 \mathrm{~K}$ [27]. CMK-3 OMCs have been proven stable even under acidic conditions, and they exhibit a unique hydrophobic affinity toward organic reactants and solvents [28]. In our previous work, a Pt/CMK-3 catalyst was successfully applied for the liquid-phase hydrogenation of benzaldehyde and its derivatives [23], and was also proven to be active and enantioselective in the asymmetric hydrogenation of $\alpha$-ketoesters after modification with cinchona alkaloids [25].

Encouraged by these achievements, we aimed to extend the applications of the Pt/CMK-3 catalyst to include the liquid-phase hydrogenation of nitrobenzene and its derivatives under 4.0 MPa hydrogen pressure, and at ambient temperature. Notably, the TOFs achieved using the Pt/CMK-3 catalyst were greater than $26.6 \mathrm{~s}^{-1}$ for the hydrogenation of most nitroarene compounds in ethanol, and a TOF of $43.8 \mathrm{~s}^{-1}$ was achieved for 2-methyl-nitrobenzene. To the best of our knowledge, this TOF value is the highest determined to date for the hydrogenation of nitrobenzene using Pt-related catalysts. Moreover, the Pt/CMK-3 catalyst could be easily recycled, and could be reused at least fourteen times without loss in activity or selectivity for the hydrogenation of nitrobenzene in ethanol. The Pt nanoparticles were stable on the CMK-3, and the amount of Pt that had leached into the filtrate after the reaction was below the detection limit of ICP-AES.

\section{Experimental}

\subsection{Materials}

Hydrogen hexachloroplatinate (IV) hexahydrate $\left(\mathrm{H}_{2} \mathrm{PtCl}_{6} \cdot 6 \mathrm{H}_{2} \mathrm{O}\right)$ and other chemicals were of analytical grade. Pluronic $123\left(\mathrm{EO}_{20} \mathrm{PO}_{70} \mathrm{EO}_{20}, M_{\mathrm{W}}=5800\right)$ was purchased from Sigma-Aldrich. Nitrobenzene and its derivatives were purchased from Aladdin, and were used as received. The commercial Pt/C (5\%) catalyst and sodium formate were purchased from Alfa Aesar. Sucrose, tetraethoxysilane (TEOS), hydrochloric acid ( $\mathrm{HCl}, 37 \%)$, concentrated sulfuric acid $\left(\mathrm{H}_{2} \mathrm{SO}_{4}, 98 \%\right)$, and ethanol were purchased from Sinopharm Chemical Reagent Co., Ltd.

\subsection{Preparation and characterization of the catalyst}

The CMK-3 OMCs were synthesized using mesoporous silica SBA-15 as the hard template, sulfuric acid as the carbonization catalyst, and sucrose as the carbon source [27]. 5\% Pt/CMK-3 catalyst was prepared according to the method reported by $\mathrm{Li}$ et al. $[25,29]$. Specifically, the CMK-3 was impregnated with an aqueous solution of $\mathrm{H}_{2} \mathrm{PtCl}_{6}$ for $6 \mathrm{~h}$, under magnetic stirring. The mixture was then evaporated to remove the excess solvent, and this was followed by a drying at $353 \mathrm{~K}$ overnight. The catalyst precursor was subsequently reduced in an aqueous solution of sodium formate at $363 \mathrm{~K}$ for $2 \mathrm{~h}$. The mixture was then washed using plenty of water, to remove chlorine ions, and dried at $353 \mathrm{~K}$ overnight. The obtained catalyst was denoted as Pt/CMK-3.

X-ray diffraction (XRD) patterns of the samples were collected using a Bruker D8 Advance instrument, using $\mathrm{Cu} K_{\alpha}$ ra- 
diation. Nitrogen adsorption-desorption isotherms were measured at $77 \mathrm{~K}$ using a Quantachrome Autosorb-3B system, after the samples were evacuated for $10 \mathrm{~h}$ at $373 \mathrm{~K}$. The Brunauer-Emmet-Teller (BET) specific surface area was calculated using adsorption data recorded in the relative pressure range from 0.05 to 0.35 . The pore size distribution curves were calculated via analysis of the adsorption branch of the isotherm, using the Barrett-Joyner-Halenda (BJH) algorithm. The actual composition of the samples was characterized using energy dispersive X-ray spectroscopy (EDX), using a Horiba EMAX spectrometer in combination with a Hitachi S-4800 scanning electron microscope (SEM). Transmission electron microscopy (TEM) images were recorded on an FEI Tecnai G2-TF30 electron microscope operated at an accelerating voltage of $300 \mathrm{kV}$. X-ray photoelectron spectroscopy (XPS) measurements were performed on the samples using a Thermo Fisher Scientific ESCALAB 250 spectrometer, with an Al $K_{\alpha}$ radiation (1486.6 eV) incident beam. The CO chemisorption of the samples was measured at $308 \mathrm{~K}$ using a Quantachrome CHEMBET-3000 pulse chemisorption analyzer, after the samples were pretreated in a $5 \% \mathrm{H}_{2} / 95 \%$ Ar flow at $673 \mathrm{~K}$ for $2 \mathrm{~h}$. The mean particle size (cubic model) were estimated from the measured CO uptake, assuming a cross-sectional area for a surface platinum atom of $8.0 \times 10^{-20} \mathrm{~m}^{2}$ and a stoichiometric factor of one, using nominal platinum concentrations. The amount of $\mathrm{Pt}$ atoms leached into the solution after the reaction was detected using Thermo Elemental IRIS Intrepid II XSP inductively coupled plasma-atomic emission spectroscopy (ICP-AES).

\subsection{Catalytic tests}

For the typical hydrogenation of nitrobenzene, $50 \mathrm{mg}$ or 25 mg of the $5 \% \mathrm{Pt} / \mathrm{CMK}-3$ catalyst was pretreated in a specially designed quartz tube under $\mathrm{H}_{2}$ atmosphere and at $673 \mathrm{~K}$ for $2 \mathrm{~h}$, before use. The catalyst was then transferred to a $100 \mathrm{~mL}$ autoclave, and mixed with the solvent and substrate. The reaction began when 4.0 MPa of hydrogen pressure was introduced under stirring at $298 \mathrm{~K}$. The reaction was stopped after a designated period, and the products were analyzed using gas chromatography (GC), using an instrument equipped with a capillary column (DM-WAX, $30 \mathrm{~m} \times 0.32 \mathrm{~mm} \times 0.25 \mu \mathrm{m}$ ).

\section{Results and discussion}

\subsection{Characterization results of the catalyst}

The structure of the CMK-3 OMCs was characterized before and after Pt loading, using XRD. Fig. 1 shows low-angle and wide-angle XRD patterns of CMK-3, and the Pt/CMK-3 catalyst. Similar to CMK-3, the Pt/CMK-3 catalyst exhibited an intense diffraction peak and two weak peaks (Fig. 1(a)), which were attributed to the (100), (110), and (200) planes of the hexagonal structure $(\mathrm{p} 6 \mathrm{~mm})$, respectively. This indicated that the well-ordered, mesoporous, p6mm-symmetrical structure of the CMK-3 OMCs was maintained even after loading with the Pt nanoparticles. The wide-angle XRD patterns for the CMK-3 and
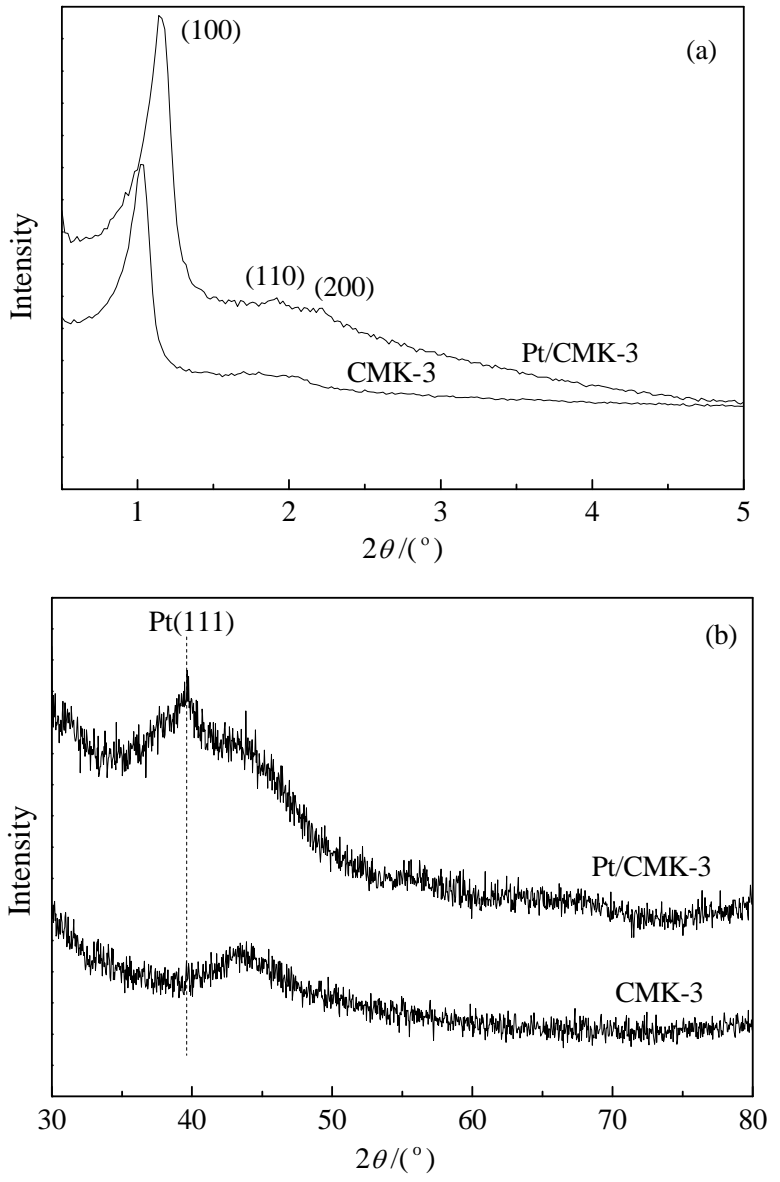

Fig. 1. Low-angle (a) and wide-angle (b) XRD patterns of the CMK-3 and the Pt/CMK-3 catalyst.

the Pt/CMK-3 catalyst (Fig. 1(b)) showed that the characteristic peak assignable to the $\operatorname{Pt}(111)$ plane was very broad, suggesting that the Pt particles were well dispersed, and that the particle size was relatively small.

The well-ordered mesoporous structure of the CMK-3 support was further confirmed by the $\mathrm{N}_{2}$ sorption isotherms measured for the Pt/CMK-3 catalyst (Fig. 2). Both the CMK-3 and the Pt/CMK-3 catalyst displayed the typical type-IV hysteresis loop in the relative pressure range from 0.45 to 0.8 (Fig. 2(a)), further demonstrating that the mesoporous structure of CMK-3 was maintained during and after the loading with the Pt nanoparticles. For clarity, the physicochemical parameters for the CMK-3 and the Pt/CMK-3 catalyst are summarized in Table 1. Briefly, the BJH pore size distribution was centered at $3.5 \mathrm{~nm}$ (Fig. 2(b)), for both the CMK-3 and the Pt/CMK-3 catalyst. The BET surface area for CMK-3 was $1325 \mathrm{~m}^{2} / \mathrm{g}$, and a reduced value of $1290 \mathrm{~m}^{2} / \mathrm{g}$ was measured for Pt/CMK-3. The Pt/CMK-3 catalyst also had an adequate pore volume of $1.18 \mathrm{~cm}^{3} / \mathrm{g}$, slightly smaller than that of CMK-3.

The morphology of the CMK-3 and the Pt/CMK-3 was characterized using SEM and TEM. As shown in Fig. 3(a) and (b), the CMK-3 reserved the p6mm symmetry as replicas of SBA- 15 . The ordered mesoporous structure of the CMK-3 was retained in the Pt/CMK-3, as revealed in Fig. 3(c) and (d). The Pt particle 

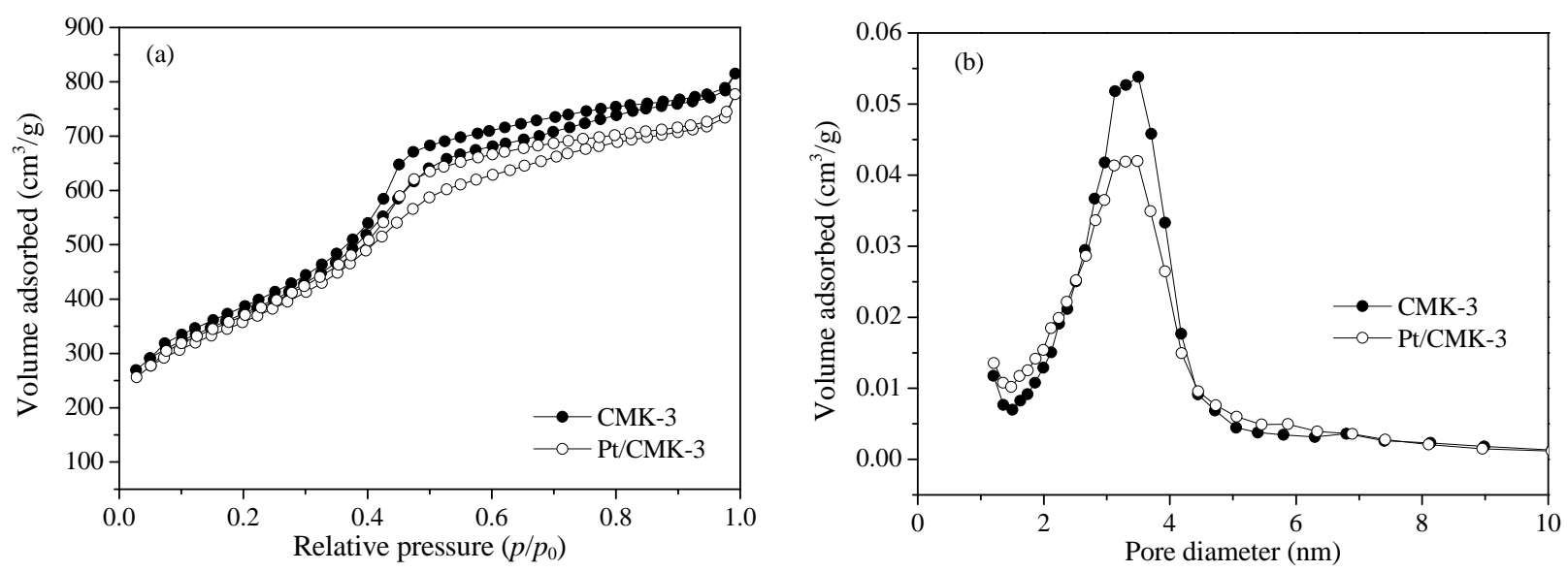

Fig. 2. $\mathrm{N}_{2}$ adsorption-desorption isotherms (a), and pore size distribution (b) for CMK-3, and the Pt/CMK-3 catalyst.

size distribution in the Pt/CMK-3 catalyst was first characterized using TEM. As displayed in Fig. 4(a), the Pt nanoparticles were uniformly dispersed on the CMK-3, and the size distribution was centered in the range of $1.5-2.5 \mathrm{~nm}$. The Pt particle size and dispersion were also calculated from the CO chemisorption on the Pt/CMK-3 catalyst. The average Pt particle size was approximately $2.5 \mathrm{~nm}$, with a dispersion of $43.7 \%$. The actual Pt loading in the final Pt/CMK-3 catalyst was measured using EDX; the actual Pt loading was $4.7 \%$, slightly lower than the nominal value.

\section{Table 1}

Physicochemical parameters of CMK-3, Pt/CMK-3, and related samples and conversions of nitrobenzene achieved using different Pt catalysts.

\begin{tabular}{lccccc}
\hline Sample & $\begin{array}{c}S_{\text {BET }} \\
\left(\mathrm{m}^{2} / \mathrm{g}\right)\end{array}$ & $\begin{array}{c}D_{\mathrm{P}} \\
(\mathrm{nm})\end{array}$ & $\begin{array}{c}V_{\mathrm{P}} \\
\left(\mathrm{cm}^{3} / \mathrm{g}\right)\end{array}$ & $\begin{array}{c}\text { Pt size }^{\mathrm{a}} \\
(\mathrm{nm})\end{array}$ & $\begin{array}{c}\text { Conv. }^{\mathrm{b}} \\
(\%)\end{array}$ \\
\hline CMK-3 & 1325 & 3.5 & 1.26 & - & - \\
Pt/CMK-3 & 1290 & 3.5 & 1.18 & 2.5 & 98.4 \\
Pt/C $^{c}$ & 892 & 3.8 & 1.07 & 10.3 & 88.7 \\
\hline
\end{tabular}

a The Pt particle size and dispersion was determined by CO chemisorption. ${ }^{b}$ Reaction conditions: $50 \mathrm{mg}$ of catalyst; $21 \mathrm{mmol}$ of nitrobenzene; $p\left(\mathrm{H}_{2}\right)=4.0 \mathrm{MPa} \mathrm{H}_{2} ; 1200 \mathrm{r} / \mathrm{min} ; 18 \mathrm{~mL}$ water $+2 \mathrm{~mL}$ ethanol; $10 \mathrm{~min}$; 298 K. c Purchased from Alfa Aesar.
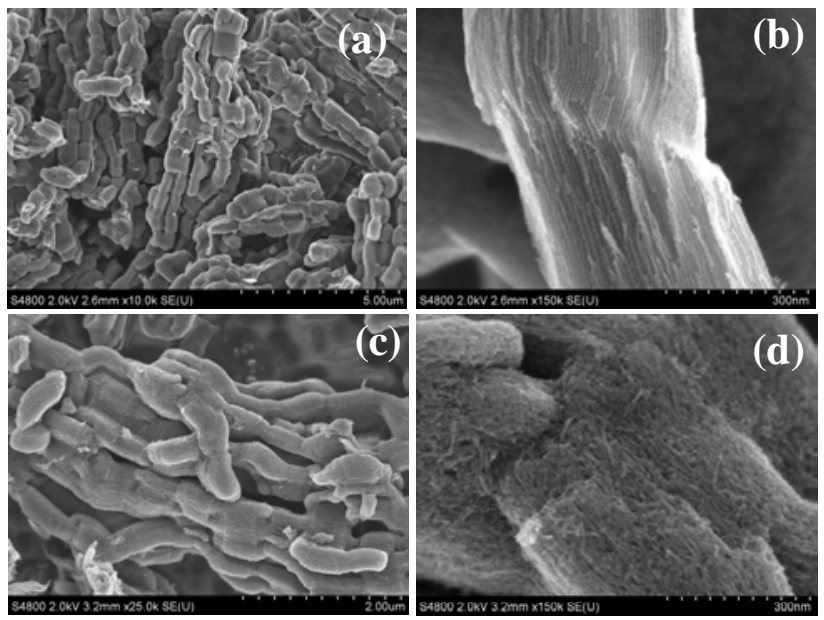

Fig. 3. SEM images of CMK-3 ((a), (b)), and the Pt/CMK-3 catalyst ((c), (d)).

\subsection{Hydrogenation of nitrobenzene and its derivatives in a mixed solvent}

In our previous work, we found that a mixed solvent containing water and ethanol with a volume ratio of 9:1 was a better choice for the hydrogenation of benzaldehyde using the Pt/CMK-3 catalyst, in comparison with neat ethanol or other organic solvents [23]. Hence, we chose this mixed solvent to determine the kinetic profile for the hydrogenation of nitrobenzene using the Pt/CMK-3 catalyst. As shown in Fig. 5, the Pt/CMK-3 catalyst provided a conversion of $34.3 \%$ within 5 min. The conversion increased quickly as the reaction proceeded. The reaction was almost finished within $10 \mathrm{~min}$, yielding $98.4 \%$ conversion, with a selectivity for aniline of over $99 \%$. For comparison, a commercial $5 \% \mathrm{Pt} / \mathrm{C}$ catalyst purchased from Alfa Aesar, and was applied for the hydrogenation of nitrobenzene under the same conditions. As listed in Table 1, the BET surface area of the commercial Pt/C catalyst was 892
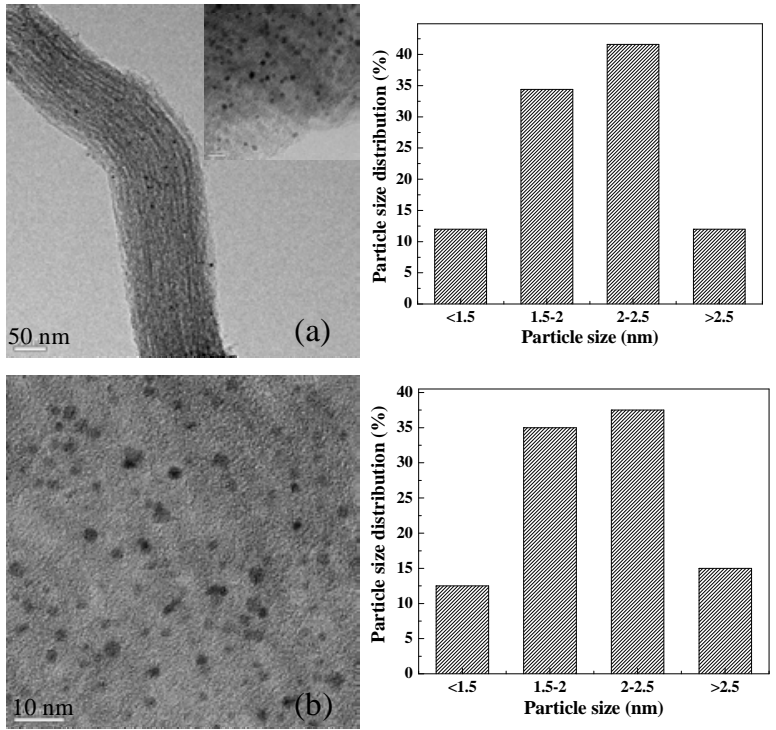

Fig. 4. TEM images of the fresh (a), and used (b) Pt/CMK-3 catalyst, and the corresponding particle size distributions. 


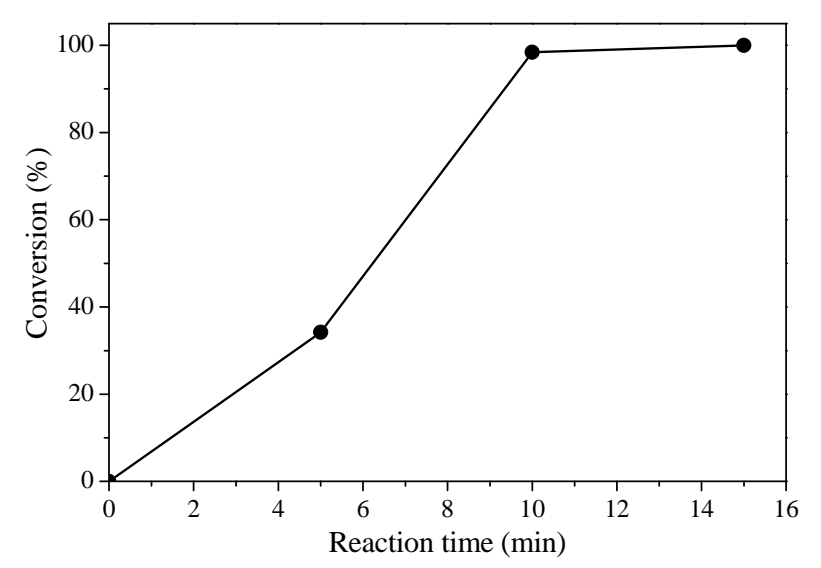

Fig. 5. Kinetic profile of the hydrogenation of nitrobenzene performed using the Pt/CMK-3 catalyst. Reaction conditions: $50 \mathrm{mg}$ of Pt catalyst; $21 \mathrm{mmol}$ of nitrobenzene; $18 \mathrm{~mL}$ of water, and $2 \mathrm{~mL}$ of ethanol; $4.0 \mathrm{MPa}$ of $\mathrm{H}_{2}$ pressure; $1200 \mathrm{r} / \mathrm{min} ; 298 \mathrm{~K}$.

$\mathrm{m}^{2} / \mathrm{g}$, and the pore volume was $1.07 \mathrm{~cm}^{3} / \mathrm{g}$. The Pt/C catalyst had an average Pt particle size of $10.3 \mathrm{~nm}$, with a dispersion of $11.0 \%$. The commercial $\mathrm{Pt} / \mathrm{C}$ catalyst yielded a conversion of $88.7 \%$ within $10 \mathrm{~min}$, lower than that obtained using the $\mathrm{Pt} / \mathrm{CMK}-3$ catalyst under the same conditions. Compared with the commercial Pt/C catalyst, the Pt/CMK-3 catalyst had two singular advantages: (1) the ordered mesoporous structure of the CMK-3, with its larger pore volume, was beneficial for the mass transportation of nitrobenzene; (2) the Pt/CMK-3 catalyst, with its smaller Pt particle size $(2.5 \mathrm{~nm})$ and higher Pt dispersion (43.7\%), led more Pt atoms to participate in the hydrogenation. Therefore, the Pt/CMK-3 catalyst was more active than the commercial Pt/C catalyst.

With these findings in hand, we extended the hydrogenation performed using the Pt/CMK-3 catalyst to a series of nitrobenzene derivatives with substituents at the phenyl ring in the mixed solvent. Table 2 gives the details of the hydrogenation results. For nitrobenzene derivatives with an electron-withdrawing group such as chlorine at the phenyl ring, 2-chloronitrobenzene yielded a $21.4 \%$ conversion under the tested

Table 2

Hydrogenation of nitrobenzene derivatives performed using different substituents at the phenyl ring, using the Pt/CMK-3 catalyst in the mixed solvent.

\begin{tabular}{|c|c|c|c|c|}
\hline Entry & R group & Conv. (\%) & Sel. ${ }^{a}(\%)$ & TOF $\left(\mathrm{s}^{-1}\right)$ \\
\hline 1 & $2-\mathrm{Cl}$ & 21.4 & $>99$ & 1.6 \\
\hline 2 & $3-\mathrm{Cl}$ & 77.7 & $>99$ & 5.2 \\
\hline 3 & $4-\mathrm{Cl}$ & 77.7 & $>99$ & 5.2 \\
\hline 4 & $2-\mathrm{CH}_{3}$ & 98.0 & $>99$ & 6.6 \\
\hline 5 & $3-\mathrm{CH}_{3}$ & 96.8 & $>99$ & 6.5 \\
\hline 6 & $4-\mathrm{CH}_{3}$ & 83.3 & $>99$ & 5.5 \\
\hline 7 & 2-MeO & 67.6 & $>99$ & 4.6 \\
\hline 8 & $4-\mathrm{MeO}$ & 29.3 & $>99$ & 1.9 \\
\hline
\end{tabular}

Reaction conditions: $50 \mathrm{mg}$ of 5 wt.\% Pt/CMK-3 catalyst; $21 \mathrm{mmol}$ of substrate; $4.0 \mathrm{MPa}$ of $\mathrm{H}_{2}$ pressure; $1200 \mathrm{r} / \mathrm{min} ; 18 \mathrm{~mL}$ of water $+2 \mathrm{~mL}$ of ethanol; $10 \mathrm{~min} ; 298 \mathrm{~K}$.

a Detected by GC. conditions, much lower than the other two isomers, which yielded conversions of approximately $77.7 \%$ (Table 2, entries 1-3). The selectivity for chloro-substituted aniline exceeded $99 \%$ in some cases, and no dechlorination occurred during hydrogenation under the tested conditions. Conversions in the range of $83 \%-98 \%$ were achieved using methyl-substituted nitrobenzenes (Table 2, entries 4-6). However, ortho- and meta-methyl substituted isomers were slightly more active than para-substituted isomers. Considering that the electron-donating ability of methoxy is stronger than that of methyl, it was expected that methoxy-substituted nitrobenzenes would yield higher conversions. As listed in Table 2, entries $7-8$, the methoxy-substituted nitrobenzene was less active (29.3\%-67.6\% conversions), compared with the methyl-substituted nitrobenzenes. In addition, para-methoxy nitrobenzene was less active than its ortho-methoxy isomer. This trend was the same as that observed for the methyl-substituted nitrobenzenes. That is, the Pt/CMK-3 catalyst showed inferior activity for nitrobenzene derivatives with an electron-donating group at the para-position of the nitro group.

Although electron-donating groups (such as methyl or methoxyl groups) at the ortho- or para- position of nitro group had similar conjugating effects [30], the electron-donating group at ortho- position of the nitro group produced a stronger inductive effect than the one at the para-position. Therefore, the ortho-methyl or methoxy substituted nitrobenzenes were more reactive than their para-substituted isomers, a result that was in good agreement with our previous findings [31]. However, the conversions achieved using the methoxy-substituted nitrobenzenes were far lower than expected. The inferior reactivity of the 2-methoxy-nitrobenzene could perhaps be explained in terms of steric hindrance of methoxy group. The methoxy at the ortho-position of nitro group, with its comparatively larger size, would have produced a stronger steric repulsion; the attack of the nitro group by the hydrogen would have been more difficult under these circumstances, and the influence of the steric hindrance was likely greater than that of the electronic effects. However, even if the steric hindrance of the methoxy group at para-position had only a small effect on the attack of the nitro group by the hydrogen, the para-methoxy nitrobenzene still produced the lowest conversion. Thus, we deduced that other influencing factors such as the solubility of the solid substrate and its mass transfer under the experimental conditions should also be taken into account, in addition to the electronic and steric effects. Most of the nitrobenzene derivatives were solid at ambient temperature and under atmospheric pressure, and they had a very limited solubility in the mixed solvent. Hence, the solubility and the mass transfer of the substrate in the mixed solvent was likely the main influencing factor under these circumstances.

\subsection{Hydrogenation of nitrobenzene and its derivatives in neat ethanol}

As a result of its structural features and surface properties, CMK-3, with its extremely high hydrophobicity, was not soluble in water, whereas some of the nitrobenzene derivatives were 
solids even at room temperature, and had very limited solubility in the mixed solvent. If the reaction was conducted in the mixed solvent in these cases, the mass transfer would likely be a key factor influencing the hydrogenation rate. Consequently, neat ethanol was applied as an alternative solvent. Surprisingly, full conversion of nitrobenzene was achieved over the Pt/CMK-3 catalyst within 5 min in ethanol; the conversion was much higher than that obtained in the mixed solvent $(34.3 \%)$ under the same conditions. A conversion of $22.2 \%$ was obtained under the same conditions when the nitrobenzene dosage was increased by five times. Inspired by the improvement in the nitrobenzene hydrogenation in ethanol, the hydrogenation of nitrobenzene derivatives was also carried out in neat ethanol using the Pt/CMK-3 catalyst.

$50 \mathrm{mg}$ of the catalyst was used in the hydrogenation of 2-chloro-nitrobenzene. Full conversion was obtained in less than 5 min in ethanol; this conversion was much higher than that obtained in the mixed solvent $(21.4 \%$ conversion in 10 $\mathrm{min}$ ). However, we noticed that the hydrogen consumption was too rapid to control during the hydrogenation process under these circumstances. To take advantage of the superior activity of the Pt/CMK-3 catalyst in ethanol, a half dosage of Pt/CMK-3 catalyst $(25 \mathrm{mg}$ ) was added for the follow-up reactions in ethanol. As listed in Table 3, all of nitrobenzene derivatives were fully converted within 5 min under the tested conditions. The selectivity was very high, with the exception of those for the chloro-substituted nitrobenzenes. According to the GC-MS results, dechlorination occurred during the hydrogenation of all of the chloro-substituted nitrobenzenes, particularly for 4-chloro-nitrobenzene; in some cases, the TOF obtained using the Pt/CMK-3 catalyst exceeded $26.6 \mathrm{~s}^{-1}$.

The reaction was so rapid that the intrinsic activity of the Pt/CMK-3 could not be revealed clearly. Therefore, representative substrates such as 2-chloro-nitrobenzene and 2-methylnitrobenzene were chosen to carry out the further reactions.

\section{Table 3}

Hydrogenation of nitrobenzene derivatives with different substituents at the phenyl ring over the Pt/CMK-3 catalyst.

\begin{tabular}{|c|c|c|c|c|}
\hline Entry & R group & Conv. (\%) & Sel. ${ }^{\mathrm{a}}(\%)$ & TOF $\left(\mathrm{s}^{-1}\right)$ \\
\hline 1 & $2-\mathrm{Cl}$ & $100^{\mathrm{b}}$ & 97.2 & - \\
\hline 2 & $2-\mathrm{Cl}$ & 100 & 91.6 & $>26.6$ \\
\hline 3 & $2-\mathrm{Cl}$ & $37.0^{c}$ & 93.5 & 28.3 \\
\hline 4 & $3-\mathrm{Cl}$ & 100 & $>99$ & $>26.6$ \\
\hline 5 & 4-Cl & 100 & 56.8 & $>26.6$ \\
\hline 6 & $2-\mathrm{CH}_{3}$ & 100 & $>99$ & $>26.6$ \\
\hline 7 & $2-\mathrm{CH}_{3}$ & $65.5^{\mathrm{c}}$ & $>99$ & 43.8 \\
\hline 8 & $3-\mathrm{CH}_{3}$ & 100 & 96.1 & $>26.6$ \\
\hline 9 & $4-\mathrm{CH}_{3}$ & 100 & 98.6 & $>26.6$ \\
\hline 10 & 2-MeO & 100 & $>99$ & $>26.6$ \\
\hline 11 & $4-\mathrm{MeO}$ & 100 & 98.7 & $>26.6$ \\
\hline
\end{tabular}

Reaction conditions: $25 \mathrm{mg}$ of 5\% Pt/CMK-3 catalyst; $21 \mathrm{mmol}$ of substrate; $4.0 \mathrm{MPa}$ of $\mathrm{H}_{2}$ pressure; $1200 \mathrm{r} / \mathrm{min} ; 20 \mathrm{~mL}$ of ethanol; $5 \mathrm{~min}$; $298 \mathrm{~K}$.

a Detected using GC.

b $50 \mathrm{mg}$ of catalyst was used.

c $105 \mathrm{mmol}$ of substrate.
The dosages of both substrates were increased by five times (to $105 \mathrm{mmol}$ ) under the constant 4.0 MPa of hydrogen pressure in these cases, while the Pt/CMK-3 catalyst dosage was maintained at $25 \mathrm{mg}$. As a result, the conversion of 2-chloro-nitrobenzene was $37.0 \%$, with the TOF reaching $28.3 \mathrm{~s}^{-1}$. The 2-methyl-nitrobenzene yielded a $65.5 \%$ conversion, with a TOF of up to $43.8 \mathrm{~s}^{-1}$. These TOF values were much higher than that reported by Ref. [14]; in that study the solvent-free hydrogenation of nitrobenzene with Pt/MWCNTs was also carried out under a constant hydrogen pressure of $4.0 \mathrm{MPa}$, but at a higher temperature (333 K). According to Ref. [14], a TOF of $66900 \mathrm{~h}^{-1}$ (equal to $18.6 \mathrm{~s}^{-1}$ ) was achieved using the Pt/MWCNTs catalyst, a value lower than those obtained using the Pt/CMK-3 catalyst in this study. The results indicated that the solubility of the substrate in the solvent played an important role, and that the excellent activity of the Pt/CMK-3 catalyst was related to the uniform distribution of Pt nanoparticles over the CMK-3, and to the structural characteristics of the support, which included a larger pore volume and a large specific surface area.

\subsection{Reusability of the Pt/CMK-3 catalyst}

The reusability of the Pt/CMK-3 was also a crucial matter to be considered. To avoid excessive loss of the catalyst in water, and in view of the high activity of the catalyst in ethanol, the recycling experiments were performed for the hydrogenation of nitrobenzene in ethanol. As shown in Fig. 6, the Pt/CMK-3 catalyst could be recycled easily, and could be reused at least fourteen times without loss in activity or selectivity for aniline (up to over 99\%). To assess the stability of the Pt nanoparticles on the CMK-3, we detected the amount of Pt that had leached into the filtrate after the reaction, using the ICP-AES technique. No typical Pt signals were detected, indicating that the amount of Pt that had leached into the filtrate was below the detection limit, and could be neglected. The used Pt/CMK-3 catalysts were also characterized after the recycling experiments using TEM. Fig. 4(b) shows that the Pt nanoparticles remained uniformly dispersed on the support after fifteen cycles, and the Pt

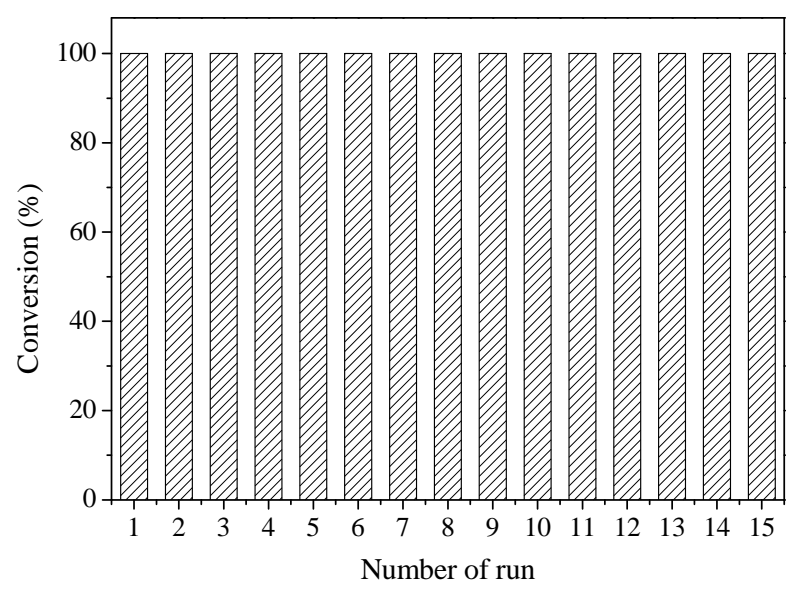

Fig. 6. Reusability of the Pt/CMK-3 catalyst in the hydrogenation of nitrobenzene in ethanol. Reaction conditions: $25 \mathrm{mg}$ of catalyst; 21 mmol of nitrobenzene; $20 \mathrm{~mL}$ of ethanol; $4.0 \mathrm{MPa}$ of $\mathrm{H}_{2}$ pressure; 1200 r/min; 5 min; $298 \mathrm{~K}$. 


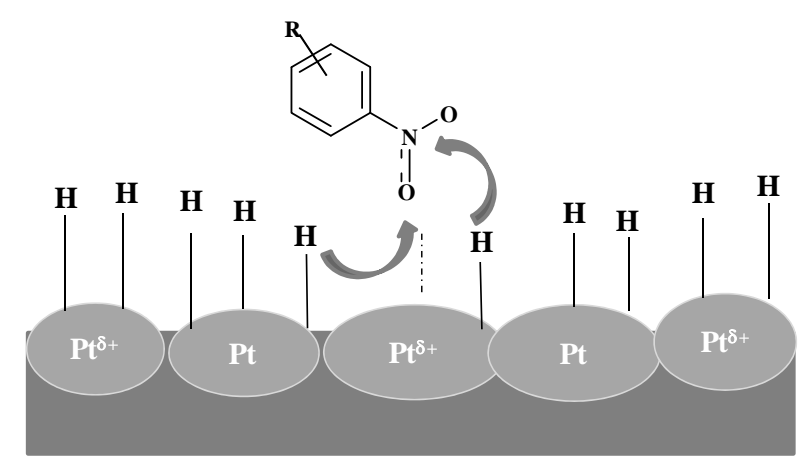

Scheme 1. Proposed adsorption/activation and hydrogenation model for the hydrogenation of nitrobenzene compounds with Pt/CMK-3 (R = $\mathrm{H}, \mathrm{Cl}, \mathrm{Me}, \mathrm{MeO}$ ).

particle size distribution was still centered at $1.5-2.5 \mathrm{~nm}$, similar to the size distribution determined for the fresh catalyst. These results further confirmed that there was a strong interaction between the Pt nanoparticles and the OMCs that contributed to the maintenance of the activity during the recycling.

\subsection{Further Discussion}

To investigate the interaction of Pt particles and the CMK-3 support, the chemical composition of the catalyst surface and the surface electronic state of Pt/CMK-3 catalyst were evaluated thoroughly using XPS. In agreement with our previous results [23], the Pt/CMK-3 catalyst with major $\mathrm{Pt}^{\delta_{+}}$species more easily activated the nitro groups, via adsorption of nitro oxygen atom bonding to the $\mathrm{Pt}^{\delta_{+}}$species (Scheme 1). Then, adjacent hydrogen atoms adsorbed on the catalyst surface attacked the nitro nitrogen or oxygen atoms, and thus hydrogenation was successfully achieved.

Regarding the hydrogenation mechanism, when Pt/AC (activated carbon) or Pt/ACC (activated carbon cloth) catalysts with a microporous structure were used, nitrobenzene was first rapidly hydrated into phenylhydroxylamine, and the intermediate then slowly transformed into aniline [8,11]. In contrast, using mesoporous CNT-supported Pt catalysts [11], the nitrobenzene was directly hydrogenated to aniline, as a result of the unusual catalytic properties of Pt/CNTs. The nitrobenzene then condensed with the product aniline to produce azoxybenzene, which converted to aniline rapidly. Considering that the mesoporous CMK-3 was similar to mesoporous CNTs, and that the chloro-substituted azoxybenzene was detected (using GC-MS) during the hydrogenation of 2-chloro-nitrobenzene, we deduced that the nitrobenzene was hydrogenated to aniline through a specific reaction pathway, likely with azoxybenzene being produced as an intermediate in this case.

\section{Conclusions}

Pt nanoparticles entrapped in CMK-3 OMCs were prepared using a simple impregnation method, and the resulting materials proved very effective for the liquid-phase hydrogenation of nitrobenzene and its derivatives under the experimental conditions investigated here. The Pt/CMK-3 catalyst was more effi- cient than a commercial Pt/C catalyst for the hydrogenation of nitrobenzene under the same conditions. Notably, the highest TOF of $43.8 \mathrm{~s}^{-1}$ was achieved using the Pt/CMK-3 catalyst in the hydrogenation of 2-methyl-nitrobenzene in ethanol. The selectivity was high in all solvents, with the exception that the hydrodechlorination of chloro-substituted nitrobenzene occurred in ethanol. Furthermore, the Pt/CMK-3 catalyst could be recovered easily, and could be reused more than fourteen times with no loss in activity, which demonstrated that the Pt nanoparticles were stabilized by the ordered mesoporous carbons.

\section{References}

[1] Mantha R, Taylor K E, Biswas N, Bewtra J K. Environ Sci Technol, 2001, 35: 3231

[2] Bell L S, Devlin J F, Gillham R W, Binning P J. J Contam Hydrol, 2003, 66: 201

[3] Fang X M, Yao S L, Qing Z, Li F Y. Appl Catal A, 1997, 161: 129

[4] Chen J X, Yao N, Wang R J, Zhang J Y. Chem Eng J, 2009, 148: 164

[5] Wang J H, Yuan Z L, Nie R F, Hou Z Y, Zheng X M. Ind Eng Chem Res, 2010, 49: 4664

[6] Zheng Y F, Ma K, Wang H L, Sun X, Jiang J, Wang C F, Li R, Ma J T. Catal Lett, 2008, 124: 268

[7] Richardson J T. Principles of Catalyst Development. New York: Plenum Press, 1984

[8] Pérez M C M, de Lecea C S M, Solano A L. Appl Catal A, 1997, 151: 461

[9] Jin S, Qian W Z, Liu Y, Wei F, Wang D Z, Zhang J C. Aust J Chem, 2010, 63: 131

[10] de Miguel S R, Vilella J I, Jablonski E L, Scelza O A, de Lecea C S M, Solano A L. Appl Catal A, 2002, 232: 237

[11] Li C H, Yu Z X, Yao K F, Ji S F, Liang J.J Mol Catal A, 2005, 226: 101

[12] Vilella I M J, de Miguel S R, Scelza O A. Chem Eng J, 2005, 114: 33

[13] Zhao Y, Li C H, Yu Z X, Yao K F, Ji S F, Liang J. Mater Chem Phys, 2007, 103: 225

[14] Sun Z Y, Zhao Y F, Xie Y, Tao R T, Zhang H Y, Huang C L, Liu Z M. Green Chem, 2010, 12: 1007

[15] Zhou H S, Zhu S M, Hibino M, Honma I, Ichihara M. Adv Mater, 2003, 15: 2107

[16] Shao Y, Xu Z Y, Wan H Q, Wan Y Q, Chen H, Zheng S R, Zhu D Q. Catal Commun, 2011, 12: 1405

[17] Lee J, Yoon S, Hyeon T, Oh S M, Kim K B. Chem Commun, 1999: 2177

[18] Ohkubo T, Miyawaki J, Kaneko K, Ryoo R, Seaton N A.J Phys Chem $B, 2002,106: 6523$

[19] Liu Z, Mi J H, Yang Y, Song Y, Deng L P. Mater Lett, 2011, 65: 3548

[20] Mahata N, Gonçalves F, Pereira M F R, Figueiredo J L. Appl Catal A, 2008, 339: 159

[21] Kim N I, Cheon J Y, Kim J H, Seong J, Park J Y, Joo S H, Kwon K. Carbon, 2014, 72: 354

[22] Ding Y, Li X H, Pan H Y, Wu P. Catal Lett, 2014, 144: 268

[23] Ding Y, Li X H, Li B, Wang H H, Wu P. Catal Commun, 2012, 28: 147

[24] Li B, Li X H, Ding Y, Wu P. Catal Lett, 2012, 142: 1033

[25] Li B, Li X H, Wang H N, Wu P.J Mol Catal A, 2011, 345: 81

[26] Su D S, Delgado J J, Liu X, Wang D, Schlögl R, Wang L F, Zhang Z, Shan Z, Xiao F S. Chem Asian J, 2009, 4: 1108

[27] Jun S, Joo S H, Ryoo R, Kruk M, Jaroniec M, Liu Z, Ohsuna T, Terasaki O.J Am Chem Soc, 2000, 122: 10712

[28] Xing R, Liu Y M, Wang Y, Chen L, Wu H H, Jiang Y W, He M Y, Wu P. Microporous Mesoporous Mater, 2007, 105: 41

[29] Li X H, Shen Y L, Xing R, Liu Y M, Wu H H, He M Y, Wu P. Catal Lett, 


\title{
Graphical Abstract
}

Chin. J. Catal., 2015, 36: 1995-2003 doi: 10.1016/S1872-2067(15)60937-8

Pt nanoparticles entrapped in ordered mesoporous carbons: An efficient catalyst for liquid-phase hydrogenation of nitrobenzene and its derivatives

Junrui Li, Xiaohong Li*, Yue Ding, Peng Wu East China Normal University

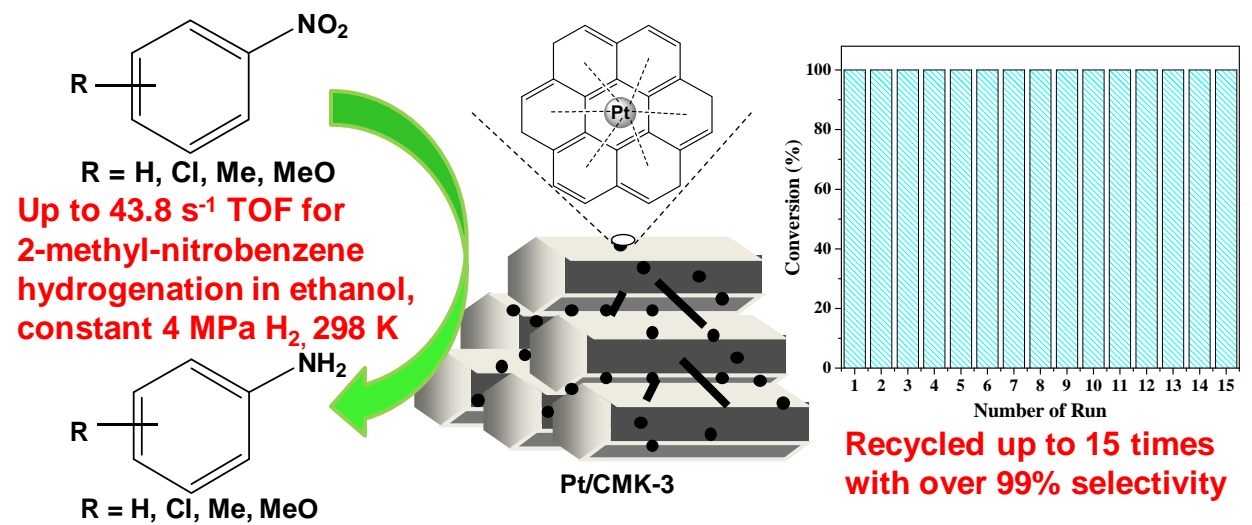

Pt nanoparticles entrapped in ordered mesoporous carbons CMK-3 served as an efficient and recyclable catalyst for the liquid-phase hydrogenation of nitrobenzenes. The TOF reached $43.8 \mathrm{~s}^{-1}$ for the hydrogenation of 2-methylnitrobenzene with the Pt/CMK-3 catalyst under optimal conditions.

2008, 122: 325

[30] Liu S B. J Chem Phys, 2014, 141: 194109
[31] Pan H Y, Li X H, Yu Y, Li J R, Hu J, Guan Y J, Wu P. J Mol Catal A, 2015, 399: 1

\section{有序介孔碳材料负载铂纳米粒子：用于硝基苯及其衍生物 液相催化氢化的高效催化剂}

\author{
李君瑞, 李晓红 ${ }^{*}$, 丁 玥, 吴鹏 \\ 华东师范大学化学与分子工程学院上海市绿色化学与化工过程绿色化重点实验室, 上海200062
}

摘要: 介孔碳材料由于具有规整的孔道结构、表面疏水性、化学惰性、大的比表面积和大的孔体积等特点, 在催化领域的应用备 受关注, 不仅可以直接用作催化剂, 还可以作为催化剂载体负载金属活性中心并用于催化反应. 介孔碳材料作为载体用于加氢反 应已有报道, 并且其催化活性明显优于活性炭材料. 有序介孔碳材料的代表之一CMK-3可以经过SBA-15翻模合成. 采用浸渍法 将氯铂酸负载到CMK-3载体上, 经过甲酸钠还原制得质量分数为 $5 \%$ 的Pt/CMK-3催化剂. 小角XRD谱表明CMK-3保留了 p6mm对 称性, 介孔结构完好; 从广角XRD谱可以看出, 金属铂粒子的衍射峰比较宽, 说明铂纳米粒子分散比较均匀. CO化学吸附和透射 电镜(TEM)的表征结果进一步证明铂纳米粒子分散得比较均匀, 平均粒子大小约为 $2.5 \mathrm{~nm}$ (CO化学吸附), EDX结果表明铂的实际 担载量为 $4.7 \%$.

将Pt/CMK-3催化剂用于硝基苯及其衍生物的液相加氢反应中, 发现溶剂对反应结果具有很大的影响. 首先参考以前的工作, 选用水和乙醇体积比 $9: 1$ 的混合溶液为溶剂. 在 $298 \mathrm{~K}$ 和 $4 \mathrm{MPa}$ 氢气条件下, $50 \mathrm{mg}$ 催化剂可以将 $21 \mathrm{mmol}$ 硝基苯在 $10 \mathrm{~min}$ 内转化 98.4\%, 产物苯胺的选择性高于 $99 \%$; 活性明显高于商品化 Pt/C催化剂(相同条件下转化率为 88.7\%). 在此基础上, 把Pt/CMK-3催 化剂用于含有不同取代基的硝基苯衍生物的液相催化加氢反应, 含有吸电子基团如氯取代的硝基苯衍生物转化率为 (21.4\%-77.7\%); 苯环上含有给电子基团如甲基时, 硝基甲苯加氢反应的转化率为(83.3\%-98.0\%); 而给电子能力更大的基团如甲 氧基取代的硝基苯衍生物的转化率却并不高. 一方面是由于电子效应导致氯取代的硝基苯衍生物活性偏低, 另一方面是由于空 间位阻导致邻位取代的硝基苯衍生物活性相对其它位置取代的衍生物转化率偏低.

考虑到部分反应物在混合溶剂中溶解度较低, 可能导致加氢反应过程受到影响, 从而影响反应结果, 所以又选用无水乙醇溶 剂进行了比较. 首先仍用 $50 \mathrm{mg}$ 催化剂于硝基苯催化加氢反应, 发现在乙醇溶剂中, $21 \mathrm{mmol}$ 硝基苯在 $5 \mathrm{~min}$ 内可以完全转化; 当把 硝基苯的量增加到 5 倍时, 转化率为 $22.2 \%$, 苯胺选择性高于 $99 \%$. 因此, 在乙醇溶剂中将催化剂用量减半, 结果在 $5 \mathrm{~min}$ 内 $21 \mathrm{mmol}$ 硝基苯衍生物均完全转化为对应的芳香胺化合物; 除了硝基氯苯发生脱氯副反应外, 其它衍生物选择性都很高. 为了更好地区分 不同取代基硝基苯衍生物的加氢活性, 将 2 -氯硝基苯和2-甲基硝基苯的用量增大至 $105 \mathrm{mmol}$, 反应过程中保持氢气压力恒为 4 
$\mathrm{MPa}$, 并使反应在 $5 \mathrm{~min}$ 后中止, 此时测得2-氯硝基苯催化加氢的TOF值为 $28.3 \mathrm{~s}^{-1}$, 而2-甲基硝基苯的TOF值高达 $43.8 \mathrm{~s}^{-1}$. X射线光 电子能谱(XPS)显示Pt/CMK-3表面含有带一定正电的铂物种, 推测此物种有助于吸附硝基的氧原子, 从而活化底物, 促进加氢反 应的顺利进行.

最后还考察了Pt/CMK-3催化剂在硝基苯加氢中的循环使用性能, 发现催化剂可以循环使用至少14次, 活性没有任何下降. 对 反应滤液进行ICP分析, 发现滤液中并没有铂离子流失; 对使用过的催化剂进行透射电镜表征也没有观察到铂粒子聚集现象, 说 明催化剂的稳定性良好.

关键词: 铂纳米粒子; 硝基苯衍生物; 液相加氢; 有序介孔碳

收稿日期: 2015-05-21. 接受日期: 2015-06-17. 出版日期: 2015-11-20.

*通讯联系人. 电话/传真: (021)62238590; 电子信箱: xhli@chem.ecnu.edu.cn

基金来源：国家自然科学基金(21273076, 21373089); 浙江师范大学浙江省省属高校“化学”重中之重学科 “先进催化材料” 教 育部重点实验室开放课题(ZJHX2013); 上海市重点学科建设项目(B409).

本文的英文电子版由Elsevier出版社在ScienceDirect上出版(http://www.sciencedirect.com/science/journal/18722067). 